\title{
Food Related Capability Deprivation
}

by

Sarah Hoffman

A thesis submitted to the Faculty of Graduate and Postdoctoral

Affairs

in partial fulfillment of the requirements for the degree of

\author{
Master \\ In \\ Philosophy
}

Carleton University

Ottawa, Ontario

(C) 2012

Sarah Hoffman 
Library and Archives

Canada

Published Heritage

Branch

395 Wellington Street

Ottawa ON K1A ON4

Canada
Bibliothèque et

Archives Canada

Direction du

Patrimoine de l'édition

395 , rue Wellington

Ottawa ON K1A ON4

Canada
Your file Votre référence

ISBN: $978-0-494-91600-1$

Our file Notre référence

ISBN: 978-0-494-91600-1
NOTICE:

The author has granted a nonexclusive license allowing Library and Archives Canada to reproduce, publish, archive, preserve, conserve, communicate to the public by telecommunication or on the Internet, loan, distrbute and sell theses worldwide, for commercial or noncommercial purposes, in microform, paper, electronic and/or any other formats.

The author retains copyright ownership and moral rights in this thesis. Neither the thesis nor substantial extracts from it may be printed or otherwise reproduced without the author's permission.
AVIS:

L'auteur a accordé une licence non exclusive permettant à la Bibliothèque et Archives Canada de reproduire, publier, archiver, sauvegarder, conserver, transmettre au public par télécommunication ou par l'Internet, prêter, distribuer et vendre des thèses partout dans le monde, à des fins commerciales ou autres, sur support microforme, papier, électronique et/ou autres formats.

L'auteur conserve la propriété du droit d'auteur et des droits moraux qui protege cette thèse. $\mathrm{Ni}$ la thèse ni des extraits substantiels de celle-ci ne doivent être imprimés ou autrement reproduits sans son autorisation.
In compliance with the Canadian Privacy Act some supporting forms may have been removed from this thesis.

While these forms may be included in the document page count, their removal does not represent any loss of content from the thesis.
Conformément à la loi canadienne sur la protection de la vie privée, quelques formulaires secondaires ont été enlevés de cette thèse.

Bien que ces formulaires aient inclus dans la pagination, il n'y aura aucun contenu manquant. 


\begin{abstract}
The current food supply system fundamentally interferes with the ability of individuals to live according to their own conception of the good. According to the framework set forth by the capabilities approach this interference can be interpreted as capability deprivation. The capabilities approach should equate to a range of possible ways of living however, the current food supply system offers only one way to organize life with regard to food. Three major consequences of the current food supply system (ignorance, instability, and source) will be used to articulate the ways in which the individual is restricted from acting according to their own conception of the good. Nussbaum's capabilities of health and safety and of free association are used to articulate food related capability deprivation. A new capability regarding the formation of the individual's conception of the good will be proposed and the same problems (ignorance, instability, and source) create capability deprivation in this area. Existing food movements are explored and exposited as potential solutions to food related capability deprivation.
\end{abstract}


Title Page

$\begin{array}{ll}\text { Abstract } & \text { ii }\end{array}$

Table of Contents iii

Introduction 1

Sec I Capabilities Approach $\quad 2$

Sec II Ignorance, Instability and Source $\quad 7$

Sec III Discussion of Health and Safety and of Free Association 10

$\begin{array}{ll}\text { Sec IV Capability of Development } & 18\end{array}$

Sec V Resolution of Capability Deprivation through Food Movements 23

Sec VI Conclusion 33

$\begin{array}{ll}\text { End Notes } & 36\end{array}$

Literature Review 
The current food supply system fundamentally interferes with the ability of individuals to live according to their own conception of the good. According to the framework set forth by the capabilities approach this interference can be interpreted as capability deprivation. The capabilities approach aims to provide citizens with a range of possible ways of living however the current food supply system offers only one way to organize life with regard to food. After briefly expositing the capabilities approach, three major consequences of the current food supply system (consumer ignorance, instability, and primary source) will be used to articulate the ways in which the state is decidedly non-neutral insofar as it interferes with the individual's ability to form and live out their own conception of the good with regard to food. Nussbaum's capabilities of health and safety and of free association will be used to articulate the ways in which the modern food supply system creates capability deprivation. A new capability regarding the development of the individual's conception of the good will be proposed and it will be argued that the same problems of the food supply system (ignorance, instability, and source) create capability deprivation in this area. There are a range of possible solutions to food related capability deprivation ${ }^{\mathrm{i}}$ which can be understood as either structural or personal in nature. Structural changes are the responsibility of the state, as the state is responsible for increasing the individual's capabilities. The rise of food movements can be interpreted as the individual's attempt to increase personal functionings with regard to food

\footnotetext{
'Food related capability deprivation does not refer to food in a basic needs sense but rather to the structure and format of the individual's relationship to food.
} 


\section{Capabilities Approach}

The capabilities approach is a philosophical framework that attempts to evaluate the basic entitlements of every human being by raising the very simple question: "What are people actually able to do and to be? What real opportunities are available to them?" 1 Capabilities can be understood as substantial freedoms, or the real opportunities individuals have to develop and then live according to their own conception of the good. Nussbaum's list of capabilities includes life, bodily health, bodily integrity, senses, imagination and thought, emotions, practical reason, affiliation, other species, play and control over one's environment. ${ }^{2}$ The list of capabilities can be used as a tool of analysis in order to establish the quality of individual's lives. As Nussbaum states, the capabilities approach focuses on "human capabilities, that is, what people are actually able to do and to be, in a way informed by an intuitive idea of a life that is worthy of the dignity of the human being." Nussbaum identifies a list of central human capabilities and argues "that all of them are implicit in the idea of a life worthy of human dignity." 4 The approach

"takes each person as an end, asking not just about their total or average wellbeing but about the opportunities available to each person. [The approach] is focused on choice or freedom, holding that the crucial good societies should be promoting for their people is a set of opportunities, or substantial freedoms, which people then may or may not exercise in action: the choice is theirs." 5

The capabilities approach thus "commits itself to respect for people's powers of selfdefinition." The capabilities approach can then be used to make normative claims about the individual's entitlements.

An understanding of capabilities requires an understanding of functioning. Functionings are the "active realization of one or more capabilities." 7 Functionings can 
be understood as the end result of having a capability set. Capabilities have value in and of themselves because promoting capabilities promotes freedom of choice. However, promoting capabilities should not equate to requiring individuals to function in a particular way. ${ }^{8}$ The distinction between capabilities and functioning will become important when discussing solutions to food related capability deprivation in Section Five. Meanwhile, the focus on substantial freedoms, or capabilities, rather than on functioning is important as doing so does not impose a particular notion of the good, but instead aims at providing a range of possible ways of living. The capability approach holds that "capabilities, not functionings, are the appropriate political goals, because room is thereby left for the exercise of human freedom." In other words, capability, not functioning, is the appropriate political goal as the capabilities are meant to be realized in different ways according to individual preferences and values.

The capability approach relies on assessments of quality of life that are not primarily focused on resources (understood as material possessions) or welfare (understood as a person's mental states) but instead on capabilities or the effective opportunities individuals have to lead lives they have reason to value. The most prominent approach to quality-of-life assessment in development economics and international policymaking previously was gross national product per capita. The capability critic of this approach is that it offers little insight into the lives of individuals. ${ }^{10}$ This is because income and wealth are not accurate measurements of the capabilities that individuals have. Individual happiness is not indicative of whether the individual's resource level is fair. As Nussbaum states, “[p]eople have differing needs for resources if they are to attain a similar level of functioning, and they also have different 
abilities to convert resources into functionings." 11 The inadequacy of measuring wellbeing by economic means can be highlighted by exploring the well-being of those with disabilities. A person in a wheelchair may have the same income and wealth as an ablebodied person and still have reduced capabilities as a consequence of their health. ${ }^{12}$ The capability approach aims to exposit and explore areas of human life that are beyond the reach of economics. For example, the capability approach is useful as it offers a way to understand the quality of life of those who are well nourished beyond merely comparing resources. Resources are inadequate as an index of well-being, because humans have varying needs for resources, and also varying abilities to convert resources into functioning. ${ }^{13}$

The capabilities approach has typically been applied in the context of international development policies, with a focus on poorer nations that are struggling to improve their quality of life. However, all nations struggle to provide their citizens with lives worthy of human dignity. In fact,

"all nations are developing nations, in that they contain problems of human development and struggles for a fully adequate quality of life and for minimal justice. All are currently failing at the aim of ensuring dignity and opportunity for each person. For all, then, the capability approach supplies insight."14

The capability approach offers a way to understand how public policy can have an impact (either positively or negatively) on the lives of individuals. Nussbaum uses the approach of the threshold level of each capability, "beneath which it is held that truly human functioning is not available to citizens; the social goal should be understood in terms of getting citizens above this capability threshold". 15 This discussion is intended to highlight 
the notion that in situations where capabilities are deprived, quality of life is negatively affected.

An important aspect of the capabilities approach is that the state remains neutral in order to allow its citizens the ability to exercise their freedom. Neutrality is the view that the state should not reward or penalize particular notions of the good life, but rather should provide a neutral framework within which different and potentially conflicting conceptions of the good can be pursued. Neutrality is the view that the state should refrain from supporting or encouraging one version of the moral, religious, and philosophical good over another. Through its policy and laws the state has a duty to refrain from supporting one conception of the good over another. ${ }^{16}$ Neutrality can be summarized by saying

"that political decisions must be, so far as is possible, independent of any particular conception of the good life or of what gives value to life. Since the citizens of a society differ in their conceptions, the government does not treat them as equals if it prefers one conception to another, either because the officials believe that one is intrinsically superior, or because one is held by the more numerous or more powerful group." 17

The importance of neutrality increases with a rise in pluralistic societies as citizens in pluralistic societies hold different moral and religious views. Understanding what it means for the state to be neutral between the moral and religious views of its citizens, however, has proved to be a difficult task as there is no single conception of neutrality that is universally accepted. ${ }^{18}$ However, problems relating to the definition of neutrality do not negate its importance as Nussbaum clearly states that the capabilities are meant to be forwarded by a neutral state. The capabilities approach advances the concept of state neutrality as the 
"capabilities are then presented as the source of political principles for a liberal pluralistic society; they are set in the context of a type of political liberalism that makes them specifically political goals and presents them in a manner free of any specific metaphysical grounding." 19

Nussbaum generally leaves the specifics of these decisions to political debate.

Nussbaum's capability approach can be criticised as it can be interpreted as perfectionist in nature. Perfectionism is the idea that the state should not strive to be neutral between different conceptions of the good, but should promote a valid or sound conceptions of the good and discourage worthless ones. ${ }^{20}$ Perfectionists hold that the state should promote excellence and/or assist its citizens in their efforts to lead worthwhile lives, even if doing so requires the state to undertake political action that is controversial or coercive. This view holds that state should, assuming that it is competent to do so assist its citizens in their efforts to lead valuable lives. ${ }^{21}$ As Nussbaum presents an objective list of capabilities the state should provide its citizens is her view perfectionist in nature? Nussbaum's capability approach is not perfectionist in nature because her list of capabilities "must be understood as a freestanding moral idea, not one that relies on a particular metaphysical or teleological view"22 as would be required by a perfectionist state. Additionally, Nussbuam's capabilities approach is not perfectionist in nature because the capabilities are intended to be forwarded by a neutral state which would support the development and execution of various conceptions of the good.

State neutrality is vital to the creation and implementation of the individual's conception of the good, and therefore to the realization of their capabilities. However, the capabilities approach is simultaneously 
"concerned with entrenched social injustice and inequality, especially capability failures that are the result of discrimination or marginalization. It ascribes an urgent task to government and public policy - namely, to improve the quality of life for all people, as defined by their capabilities." 23

The capabilities approach requires the state to create political, economic, and social institutions and opportunities for individuals to live lives rich with human dignity, according to their own conceptions of the good.

\section{Ignorance. Instability and Source}

The food supply system and its coinciding distribution system has a negative effect on the individual's ability to live out their conception of the good with regard to food. This is because the food supply system creates problems relating to ignorance, instability, and source. These problems are a consequence of a non-neutral state that upholds institutions which prioritize one conception of the good with regard to food, preventing the individual from living out their personal conception of the good with regard to food.

The discovery of synthetic nitrogen liberated the farm from biological constraints and allowed industrial agriculture, or agribusiness, to emerge. ${ }^{24}$ Industrial agriculture, with its tenants of industrial efficiency has supported the emergence of monocultures. Corn, in particular, has become a monoculture. ${ }^{25}$ Moving that mountain of corn - finding the people and animals to consume it, the cars to burn it, the new products to absorb it, and the nations to import it - has become the principle task of the industrial food system, because the supply of corn vastly exceeds the demand. ${ }^{26}$ The Standard American Diet (SAD) is characterized as a diet high in meat, eggs, dairy and refined carbohydrates while 
simultaneously being low in fruits and vegetables. The iconic American meal of a cheeseburger with French fries washed down with a Coke and followed by an ice-crearn sundae is the epitome of this diet. The widespread adherence to this way of eating is dependent on, and a consequence of the cheap meat, dairy and eggs produced by CAFOs (Concentrated Animal Feeding Operations). ${ }^{27}$ The ways in which the state supports, encourages and praises this type of eating will be explored throughout the discussions regarding capability deprivation (Section III and Section IV) and while presenting solutions (Section V). It is important to note that government encouragement of the SAD way of eating is fundamentally antithesis to state neutrality.

The food supply system creates problems relating to ignorance as the food supply system insists that individuals act in a certain way with regard to food due to lack of options or knowledge regarding alternatives. The long and intricate supply lines required by industrial agriculture sever any link between the producer of food and its ultimate consumer. ${ }^{28}$ If the consumer is ignorant of the facts of production and stifled by laws regarding food, they remain unable to make decisions that reflect their conception of the good. In order for the state to be neutral regarding conceptions of the good, individuals have to have the ability to make decisions that represent their conception of the good with regard to food. However, the ignorance propagated by industrial agriculture prevents this.

The food supply system is inherently instable as it is dependent on an enormous and intricate economic and industrial organization. Industrial agriculture can be gravely impaired or stopped by any number of causes, none of which need be agricultural in nature. For example a trucker's strike, an oil shortage, a credit shortage, or a manufacturing error could all have devastating consequences for the food supply 
system. ${ }^{29}$ Individuals are forced into dependence on a fragile system that may not always be capable of providing for them. A neutral state with regard to food would ensure that individuals have the ability to participate in a safe, stable, and secure food supply.

The food supply system creates problems relating to source as laws surrounding food production and distribution prevent the individual from acting outside the current food supply system as food can only be legally grown, produced, and distributed according to the parameters set forth by the current food supply system. Individuals wishing to produce or procure food outside these parameters can be subject to legal action. $^{\text {ii }}$ It is because there are few alternative options available to the individual that the food supply system prevents the individual from fulfilling their conception of the good with regard to food. For the individual to form and live according to their conception of the good with regard to food the individual requires a choice with regard to food.

The current food supply system prevents the individual from forming and living their conception of the good with regard to food because it creates problems relating to ignorance, instability and source. In order for the state to respect capabilities with regard to food, the individual has to be able to form a conception of the good with regard to food, have the ability to participate in a safe, stable, and secure food supply, and the individual has to have a choice with regard to the food supply system they participate in. The capability approach frames the problem of food related capability deprivation in a

\footnotetext{
"An Ottawa man, Mark Tijssen was recently charged (Nov 2010) with operating an unlicensed slaughterhouse and failing to have an animal inspected because he shared $40 \mathrm{lbs}$ of pig meat with a friend. Under provincial law, individuals can slaughter animals for personal use, but it is an offense to share meat with others without being licenced.
} 
way that shows the potential problems, consequences and results of enforcing a particular type of interaction with food.

\section{Discussion of Health and Safety and of Free Association}

Using Nussbaum's capabilities of health and safety and of free association we can articulate food related capability deprivation by articulating the capability deprivation that emerges as a consequences of the three problems highlighted above (ignorance, instability, and source). Nussbaum's capabilities entitled 'Bodily Health', and 'Bodily Integrity' can be collided under the heading of general health and safety. Capabilities associated with bodily health require the individual to retain the ability to live to the end of human life of normal length, without dying prematurely or experiencing a reduced quality of life, such that life becomes not worth living. ${ }^{30}$

The food supply system creates problems relating to ignorance. Industrial agriculture is producing more food than ever before, but evidence is building that the vitamins and minerals in food are declining due to changes in food production. For example, meat from grass-fed animals is higher in omega-3 fatty acids. However when "cattle are taken off omega-3 rich grass and shipped to a feedlot to be fattened on omega-

3 poor grain, they begin losing their store of this beneficial fat." ${ }^{31}$ The structure of industrial agriculture creates a final product that has fewer nutrients then that product may have had in the past. In response to the declining nutritional value of food, industrial agriculture has created pharmafoods, which are foods deliberately designed by their manufactures to create specific physical or psychological effects in those who consume them. An example of such a pharamafood is butter-like yellow fat spread designed to 
decrease the level of cholesterol in blood. Pharamafoods are dangerous as such prescription foods "could become the equivalent of making powerful drugs - hitherto available only on a doctor's prescription - easily obtainable on nothing more than the mere whim of every supermarket shopper." ${ }^{32}$ The structure of industrial agriculture interferes with the individual's capabilities by making it difficult for the consumer to acquire accurate knowledge with regard to the nutritional value of food. This lack of knowledge, or ignorance, makes it difficult for the individual to form a conception of the good with regard to food.

The instability of the food supply system has the potential to have enormous health consequences for individuals. The food supply system is inherently fragile as it is dependent on an enormous and intricate economic and industrial organization. The supply of industrial food can be impaired or interrupted by any number of causes, none of which need be agricultural in nature. A trucker's strike, an oil shortage, a credit shortage, or a manufacturing error could have catastrophic consequences for the food supply system. As Berry states, the notion that

"this population can continue to eat through shortage, strike, embargo, riot, depression, war - or any of the other large-scale afflictions that societies have always been heir to and that industrial societies are uniquely vulnerable to - is not a certainty or even a faith; it is a superstition. ${ }^{33}$

The fragility of the food supply system is illustrated by the 1970 PBB catastrophe in Michigan in which a manufacturing error caused widespread health consequences as "nine million residents consumed contaminated meat and milk for a year after a Michigan chemical plant mistakenly added PBB (polybrominated biphenyl) - a toxic fire retardant - to dairy cattle feed, and distributed it to farms throughout the state". ${ }^{34}$ In general, the 
instability of the food supply has worrying consequences for the health and safety of the population as individuals may not always be able to acquire a supply of safe, healthy, and nutritious food.

The food supply system is plagued by problems relating to source. Consumers and producers are so disconnected that the state has implemented regulation. Regulation, labelling and legal liability are consequences of, and required because the food supply system acquires food from one primary source (agribusiness). Regulation and legal liability are required because producers are not held accountable by, or to consumers within the current system. As Michael Pollan states "food safety didn't become a national or global problem until the industrialization of the food chain attenuated the relationship between food producers and eaters" ${ }^{35}$ Laws regarding sanitation and hygiene are important. However, large scale facilities do not guarantee safe practices and simply by virtue of scale, smaller production facilities do not carry the same risk potential as large facilities, as they have a much smaller range of distribution. The regulation of industrial food production prevents individuals from having a choice with regard to food. For example, a small apple cider producer is prevented from selling apple cider without processing it by pasteurization or irradiation, which would destroy important nutrients and enzymes. As Ellix Katz states, "an accomplished fruit gleaner with a human-powered mechanical press can't set up a small-time occasional cider stall at a farmer's market without diminishing his product and investing in expensive equipment to do so."36 Choice is required for the individual to express their conception of the good and a system in which there is one primary source fundamentally interferes with that ability. 
As functioning is understood as the realization of one's capabilities, increased capabilities in the area of health and safety would lead to increased functioning for the individual. Increased capabilities in this area would increase the individual's ability to make choices that align with their views on health and safety. The individual would have the ability to make choices regarding the nutritional quality of food that would reflect their own conception of the good. For example, the individual would have the ability to choose between raw, unpasteurised cider made from apples gleaned from industrial fields, raw, unpasteurised cider made from local, organic apples, or cider made from local, conventional apples among other choices. The individual would have the ability to choose the type of cider that aligns with their conception of health.

The second capability that can be explored, as affected by problems of ignorance, instability, and source, is that of free association. According to the capability approach, individuals should have the freedom to form and express attachments to things and people within a structure that does not create fear and anxiety for doing so. More generally, the capabilities approach supports the individual's ability to form a conception of the good and to engage in critical reflection about the planning of one's life. Aligned with this capability, is the ability to affiliate freely with others. An additional capability outlined by Nussbaum, is the ability to live with concern for and in relation to animals, plants and the animal world more generally. ${ }^{37}$ However, the problems of ignorance, instability and source created by the food supply system result in food related capability deprivation in the area of free association.

Laws surrounding food production and distribution encourage consumer ignorance because laws which prevent the individual from acting outside the current food 
supply system prevent them from fulfilling their conception of the good. ${ }^{\text {iii }}$ Laws regulating food are widespread and

"the rules make small-scale traditional food production and distribution almost impossible. Selling home-baked bread, or any food prepared in a home kitchen, is prohibited by most, if not all, health codes in the United States. Livestock for sale... may not be slaughtered by the farmers who raise them; instead they must be trucked to anonymous factory-like commercial slaughterhouses. Milk and other dairy products may not be sold without pasteurization, which diminishes nutritional quality, digestibility, and flavor. Cider, too, is nearly always required to be pasteurized or irradiated. In other words, real food, increasingly illegal, is being replaced by processed food products." 38

The individual's ability to associate with others over and through food is restricted by legal barriers that prevent the individual from acting in ways that he otherwise might choose. The individual is encouraged to remain ensconced within the dominate framework regarding food. This encourages individual ignorance regarding alternative conceptions of the good with regard to food.

The inherent instability of the current food supply system fundamentally interferes with free association. Corporate control combined with problems resulting from the nature of economic exchange gives rise to instability. The global food system requires large quantities of standardized and uniform products that need to be available year round. Due to these requirements, food processors enter into formal contracts with individual farmers to ensure sufficient supplies. The economically independent, selfreliant farmer has, since the rise of industrial agriculture, often been reduced to a producer of basic commodities for large corporations. ${ }^{39}$ The global economy threatens

\footnotetext{
iii For example, Ottawa municipal by-law No. 2003-77 classifies chickens as livestock which makes it illegal to raise chickens within city limits. Urban Hens Ottawa is working to change this by-law.
} 
food security by separating consumers from the food supply system and allowing corporations, with no allegiance to countries or their citizens, full reign of the food supply system. Corporate control over the food supply system creates a system in which a single company sells seed to the farmer, operates the grain elevator, owns the railroad and the port facility, buys the grain from the farmer and processes the raw material into food. Currently, the system is based on comparative advantage. The logic of comparative advantage dictates that countries should buy low and sell high regardless of a product's importance for the local culture and economy as doing so would theoretically lead to cheaper food for all of the world's consumers. In actuality it leads to dependence on foreign food suppliers and local government policies that are destructive. ${ }^{40}$ Corporate control of the food supply system illustrates the problems that arise from the current economic marketplace.

The marketplace emphasis on money has never worked well in agriculture because the economics of farming are very different from other sectors of the economy. In most sectors falling material prices allow for more sales at a lower price, however the agricultural sector is different because of the special nature of the consumer, who can only eat so much food, no matter how cheap it gets. Food industry executives refer to this as the problem of the fixed stomach. ${ }^{41}$ Corporate control and the nature of the market economy reduces the individual's ability to freely associate with others because this structure creates alienation.

Marx's theory of alienation describes the malaise of modern society. Alienation is both a deeply personal and psychological issue as well as a public product of the modern world. Individuals can be alienated from the product of their labour but collective 
alienation is also possible. Virtually everything individuals encounter is either created or transformed by human endeavours. This includes the market and when we succumb to the notion that the market renders some forms of behavior rational and others irrational we become dominated by the market. ${ }^{42}$ Alienation results in reduced capabilities regarding free association because alienation (combined with corporate control and nature of the economic marketplace) results in an inherently instable food supply system.

The food supply system is inherently instable because it is ruled by the logic of corporations and economics which are always in flux. The interaction of corporate control, the nature of the marketplace, and the malaise of modern society is immensely complicated. The consequences of which can be devastating for communities. For example, exporting North American forms of agriculture resulted in negative consequences "both technically (failing over the long-term to produce the expected higher yields) and socially (failing to convince highly knowledgeable local farmers that such a massive change in technique and expenditure was really necessary). ${ }^{, 43}$ Before the late 1970's, the common response to famine and hunger was food aid or "attempts to correct the assumed naiveté and backwardness of non-Northern farmers. ${ }^{, 44}$ However, by the late 1970's many organizations "were reporting that the ex-colonies of the so-called Third World were in worse shape than ever..." 45 In response, non-governmental organizations began experimenting with more sophisticated notions of participatory development. ${ }^{46}$ The exportation of North American farming strategies to Third World countries illustrates the instability, and resulting problems, of our food supply system. This instability prevents the individual from having the ability to participate in a safe, stable, and secure food supply. 
The food supply system purports to offer a plethora of choice however it remains plagued by problems of source. The growth of the American food industry will always bump up against this troublesome biological fact: try as we might, each of us can eat only fifteen hundred pounds of food a year. After all there is a biological limit to how much food we can each consume without exploding. For the food industry, this means that there is a natural rate of growth somewhere around one percent per year, which is the growth of the population. The solution, for the food industry is to figure out how to get individuals to spend more money for the same three quarters of a ton of food, or to entice them to actually eat more than that. ${ }^{47}$ It is these goals of the food industry that lead to and compound problems related to food related capability deprivation. For example, the food industry has done a good job of persuading us that the forty-five thousand items or SKUs (stock keeping units) in the supermarket represent genuine variety rather than so many clever arrangements of molecules extracted from the same plant. ${ }^{48}$ The lack of real choice that is a main component of the current food supply system fundamentally opposes the capabilities approach as the capabilities approach insists on offering individuals choice from which to fulfill their conception of the good with regard to food.

As functioning is understood as the realization of one's capabilities, increased capabilities in the area of free association would lead to increased functioning for the individual. Increased capabilities in this area would increase the individual's ability to make choices that align with their views on free association. The individual would have the ability to make choices regarding the type of economic exchange they participate in and that reflects their own conception of the good. For example, the individual may choose to participate in a free market exchange, participate exclusively through 
cooperatives, or to avoid the economic market entirely. The individual would have the ability to choose the type of economic exchange that aligns with their conception of free association.

In summary of the issues presented, the current food supply system prevents individuals from living their diverse conceptions of the good because it creates problems relating to ignorance, instability, and source. In order for the state to respect capabilities with regard to food, the individual has to be able to form a conception of the good with regard to food, have the ability to participate in a safe, stable, and secure food supply, and the individual has to have a choice with regard to the food supply system they participate in. The capability approach frames the problem of food related capability deprivation in a way that shows the potential problems and consequences of enforcing a particular type of interaction with food. The consequences of capability deprivation can be seen through the discussion of Nussbaum's capabilities of health and safety and of free association.

\section{Capability of Development}

The new capability proposed concerns the development of one's conception of the good. The capability proposed concerns the individual's ability to create, form, maintain, challenge and develop a full and articulate conception of the good. This capability is intended to promote and protect the structures (both public and private) that help individuals create their own conception of the good. It proscribes the ability to participate socially in a specific way such that the interaction can give rise to a personal conception of the good. Nussbaum maintains that her approach "focuses on the protection of areas of freedom so central that their removal makes life not worthy of human dignity." ${ }^{49}$ It 
seems intuitive that a life without the ability to develop a conception of the good is a life without human dignity.

In proposing a new capability, a general understanding of how new capabilities can potentially fit into Nussbaum's capability approach is important. The capabilities approach does not “...claim to be a complete political doctrine, since it simply specifies some necessary conditions for a decently just society, in the form of a set of fundamental entitlements of all citizens." ${ }^{, 50}$ Nussbaum articulates that her list is not comprehensive and "if it turns out to lack something that experience shows to be a crucial element of a life worthy of human dignity, it can always be contested and remade." ${ }^{51}$ In order for the capabilities to be revised, however, arguments showing that that capability is necessary to human dignity must be provided. Nussbaum claims that this has to be done through a process of discussing how the proposed capability illustrates and illuminates existing relationships. $^{52}$

The capability of development differs from Nussbaum's capability of affiliation in which it is stated that individuals should have the ability to "engage in social interactions" and that "protecting this capability means protecting institutions that constitute and nourish such forms of affiliation, and also protecting the freedom of assembly and political speech." ${ }^{, 53}$ The capability of development proposed differs in an important way as it aims to protect capabilities which help maintain, enforce and create the individual's conception of the good. The capability of development will ensure that the individual is able to accurately articulate and form their personal conceptions of the good. The capability of free association would ensure that individuals have the ability to meet and associate with the intention of creating a bake sale for their church bazaar but it 
would not ensure that individuals have the ability to question the nature or fundamental tenants of the church itself. The individual's ability to question, collaborate, form and make specific their conception of the good with regard to food is important and unique to the capability of development. The capability of free association aims to ensure that individuals are free to associate with others that share their conception of the good. For example, the capability of free association would ensure that vegans would have the ability to associate with other vegans. However, the capability of development aims to ensure that that association has the capability to be of a specific nature. The capability of development aims to ensure that vegans are able to associate with one another in a way that ensures their ability to question, collaborate, form, and make specific their views and conception of the good.

The capability of development aligns with Nussbaum's capability of practical reasoning. Practical reasoning entails the ability to "form a conception of the good and to engage in critical reflection about the planning of one's life." ${ }^{.54}$ The capability of practical reasoning "entails protection for the liberty of conscience and religious observation"." The capability of development presented aligns closely with Nussbaum's capability of practical reasoning but maintains the importance and specifics of free association in the way proscribed above. The capability of development requires the abstract support of practical reasoning which allows the individual freedom to form and engage in critical reflection about one's life. However, the specifics of free association in which the individual requires social space to question, collaborate, form and make specific their conception of the good remains important. The specifics of these capabilities are collided under the capability of development as the individual requires both a specific social 
interaction and a theoretical importance of practical reasoning in order to truly develop their own conception of the good.

The same three problems of the food supply system (ignorance, instability and source) can be applied to the capability of development to illustrate potential food related capability deprivation. The ignorance created and propagated by the food supply system severely stifles the individual's ability to form a conception of the good. In order to develop a conception of the good one requires information regarding the choices available. Agribusiness restricts access to information regarding food production and general food movements present an unbalanced view of various food choices. In order for food choices to reflect the individuals' conception of the good the individual has to access and understand the various implications of their choices. For example, North Americans tend to take pineapples, bananas and citrus for granted "but once upon a time they were rare and treasured delights, the proverbial orange in the Christmas stocking." 56 Imported fruit is associated with expensive, resource intensive air travel. It is important for the individual to understand the social, environmental, and economic costs and consequences of these types of choices. For instance, while purchasing certified Fair Trade coffee may offer the individual farmer a living wage it says nothing about the fact that coffee is "a cash crop originally encouraged by colonialist administrations, (and) tends to replace subsistence crops in local agriculture." ${ }^{57}$ Individuals require a complete and accurate understanding of the issue at hand in order to develop and act according to their own conception of the good. The ignorance propagated by the food supply system fundamentally affects the ease in which the individual is able to do so. 
The problem of instability in the food supply system has the potential to result in a very instable conception of the good for the individual. This is because the social aspect of food is important as cooking and food sharing results in information about the self being available socially. This means that by cooking and eating in a social arena, the individual is showing others facts about oneself. ${ }^{58}$ Cooking and food sharing in the public arena can solidify and identify common emotional, spiritual and social goals and values among and between individuals. For examples, vegans commonly bond and group together in the public arena which has the effect of solidifying their conception of the good as they discuss the reasons for their veganism. Overall, cooking and food sharing in the public arena solidifies and helps to create personal conceptions of the good. The problem of instability in the food supply system has the potential to result in a very instable conception of the good. This is because if the individual creates a conception of the good that relies on food procured from the fundamentally instable food supply system that conception of the good is also fundamentally instable. The instability of the food supply system results in instability in any conception of the good that relies on this food supply system.

The problem of source interferes with the individual's ability to create a conception of the good. The food supply system encourages individuals to view food as a commodity which results in the individual viewing food solely in economic terms. For most individuals, food is readily available which allows the use value of food for the satisfaction of hunger and nutritional needs to be easily trivialized while it's symbolic or exchange value has become increasingly important. For example, the exchange value of caviar is far greater than its ability to satisfy hunger. ${ }^{59}$ The commodification of food 
encourages the individual to view food in solely monetary terms however food has the potential to be illustrative of many other aspects of an individual's conception of the good. For example, food can be illustrative of an individual's status, aesthetic sensitivity or ethnic, religious, or political convictions. The commodification of the food system restricts the individual's choice regarding their relationship to food and may interfere with the individual's development of the good.

As functioning is understood as the realization of one's capabilities, increased capabilities in the area of development would lead to increased functioning for the individual. Increased capabilities in this area would increase the individual's ability to develop a personal conception of the good. The individual would have the ability to question, collaborate and make specific their conceptions of the good with regard to food. For example, increased capabilities regarding development would allow the individual to fully understand the social, economic, and environmental implications of fair trade versus non-fair trade coffee. The individual would be able to make informed choices that reflect their fully formed conception of the good with regard to food.

A new capability regarding the development of a personal conception of the good has been presented. The three problems (ignorance, instability, and source) of the food supply system result in capability deprivation in this area as well. While these problems may not entirely restrict the individual from developing a conception of the good they remain problematic in nature. 


\section{Resolution of Capability Deprivation through Food Movements}

The structural creation of food related capability deprivation was outlined by discussing the problems of ignorance, instability, and source that arise as a consequence of the food supply system. These problems result in capability deprivation in the areas of health and safety, free association and development. The state can promote an increase in capabilities through various structural changes. Individuals can support and attempt to affect structural changes through individual choices that increase their personal functioning. Food movements resist the dominance of the food supply system and can be understood as an attempt to increase the individual's functioning with regard to food.

One structural way of affecting change within the current economic system, and a crucial one for Pollan, is to shorten the supply line. Consumers need to be able to make their needs and desires known to the producers, and the producers should be able to impress on the consumer the distinction between ordinary and exceptional food, and the cost associated with those goods. ${ }^{60} \mathrm{~A}$ new paradigm, civic agriculture, envisions a structural change by localizing production. This perspective favors small, well integrated farmers who cooperate with each other in order to meet the food needs of consumers in local and global markets. Civic agriculture aims to change the driving force behind agriculture from economics to social processes. Communities within this alternative structure would buffer and shelter themselves from the homogenizing and destabilising forces of the global food system. However, such communities would have to develop the infrastructure, maintain the farmland base, and provide the technical expertise so that farmers and processors could successfully compete against the highly industrialized internationally organized corporate food system in the local marketplace. ${ }^{61}$ 
In order to increase capabilities, the state should remove laws that make civic agricultural activity difficult and costly. For example, laws surrounding abattoirs work well for industrial agriculture but the cost associated with implantation of those laws makes it financially difficult for small abattoirs. The difficulty of small farmers to comply with these laws reduces capabilities as it prevents options in the marketplace. ${ }^{\text {iv }}$

The individual can increase their functionings by increasing their participation in civic agricultural enterprises and activities. Farmer's market's provide immediate lowcost direct contact between farmers and consumers and are an effective first step for communities seeking to develop a stronger local food system. Community and school gardens can provide fresh vegetables for the local population while simultaneously teaching food production skills and increasing agricultural literacy. It is important to remember that an ideal agricultural system is diverse. This means that a totalizing civic agriculture, characterized by complete local or regional self-sufficiency would be neither practical nor desirable. Some level of international and interregional trade can be beneficial to both importing and exporting communities. ${ }^{62}$ Engaging in civic agricultural activities can increase the individual's functioning as these choices allow the individual to realize their capabilities regarding food. The widespread popularity of civic agricultural activity at the individual and community level would act as a catalysis for government level structural change which would increase capabilities.

\footnotetext{
"The consequences of laws for local abattoirs is described in the Canadian Institute for Environmental Law and Policy's publication Bringing Local Food Home: Legal, Regulatory and Institutional Barriers to Local Food (December 2008) The publication acknowledges the financial hardships that abattoir laws place on the small farmer.
} 
Changing the economic structure of the marketplace can increase capabilities and functionings. Buying local products, even in chain supermarkets, are arguably products that offer the consumer the opportunity to connect with food producers. However, the barriers created by the structure of the supermarket is so difficult to overcome that as Sally Miller states "we all devoted a certain amount of energy trying to figure out why people would ask for local but not buy it. It is as if the store were a museum - a place that curated a display of ethics..." ${ }^{63}$ From this type of consumer behavior it would appear that the very structure of the supermarket is interfering with the consumer's ability to connect with the producer, even in instances of ideological desire. Therefore a structural change is required in order to increase capabilities.

Increasing cooperatives are one way to increase capabilities. Cooperatives do not have the same economic goals as supermarkets but "cooperatives are firmly business enterprises, highly successful in the market economy, with a mandated democratic structure... their mission is to meet the member-owner's needs - not to profit, or to grow, just to meet their needs. ${ }^{, 64}$ Cooperatives allow consumers the opportunity to increase their capabilities with regard to food because the members of the cooperative have the opportunity to be involved in what their cooperative stocks. This gives the consumer the ability to actively and effectively make choices that reflect their version of the good with regard to food.

In order for the state to be neutral with regard to food the individual has to be able to choose between various economic interactions. To increase capabilities, the state should reduce legal and structural barriers to alternative economic interactions such as local food and cooperatives. Cuba provides a stunning example of how to do things 
differently in the economics of food. Cuba has created a complex web of different kinds of ownership, farm structure, worker relations and state and farm relations. Consumers and producers are brought closer together simply by virtue of shared interests. ${ }^{65}$ Reducing legal and structural barriers to alternative economic interactions would increase capabilities as it would allow the individual to live according to their own conception of the good.

Consumers who engage with food outside of the economic marketplace can increase their functioning as engaging with food outside of the economic marketplace will allow the individual to increase their capabilities. By redefining the requirements surrounding the definition of good food and introducing pleasure and quality, the Slow Food movement exposes the limitations of viewing food solely in economic terms. However, it is difficult for the Slow Food movement to overturn the hegemony of the marketplace, since as a dominate ideology of economic exchange, the current marketplace shuts out alternative perspectives. ${ }^{66}$ The consumption of road kill is increasingly injected with a political ideology in which practitioners reject "the values of consumer culture by 'transforming dishonored victims of the petroleum age into food which nourishes' " ${ }^{67}$ Wild food foraging is another way to bypass the economics of the current food supply system. Foraging has numerous benefits including the fact that wild plants are more nutritious, adapted to the environment, hardy and self-sufficient than their domesticated cousins. ${ }^{68}$

Engaging with the consumption, production, and distribution of food in noneconomic ways has the potential to reduce food related capability deprivation. As individuals voice their concerns regarding the economic structure of the marketplace and 
begin to act in alternative economic ways the state may begin to reduce structural and legal barriers to local food, cooperatives and other alternative economic structures which will likely increase capabilities. The individual can avoid the economic marketplace and procure their food in other ways which will increase their individual functioning.

Since food related capability deprivation is structurally created the ultimate solutions will also be structural in nature. However, there are food movements resisting the dominance of the food supply system, and by extension, the food related capability deprivation that accompanies it. Food movements resist the dominance of the food supply system and can be understood as an attempt to increase the individual's functioning with regard to food.

Individuals can voluntarily choose to create and nourish food relationships that are not encouraged within a system of structural food related capability deprivation. This requires the individual to merely change their mind about a particular food interaction. Food related capability deprivation can be decreased by voluntarily choosing to engage in new food definitions and new social relationships surrounding food. These encounters are likely to be fleeting in nature but have the potential to remain a source of connection within a structure that opposes them. For example, solitary dining is generally discouraged in our society but a solitary diner can approach the experience joyfully and refuse to remain disconnected from his food. Evidence of this can be seen in various religious movements that advocate a particular ritual and focus on the food. For example, according to the guidelines for food preparation in Zen monasteries food should be prepared with 
"sincere effort. Do not be idle even for a moment. Do not be careful about one thing and careless about another. Do not give away your opportunity even if it is merely a drop in the ocean of merit; do not fail to place even a single particle of earth at the moment of wholesome deeds." ${ }^{, 69}$

Monks believe that "if there is sincerity in your cooking and associated activities, whatever you do will be an act of nourishing the sacred body." are ancient, food movements that advocate a particular ritual and focus on food can increase individual functioning regarding food as such focus has the potential to allow the individual to realise their conception of the good with regard to food. ${ }^{v}$

Cooking and food sharing can be interpreted as a way of increasing functionings as a result of the information about food consumed being available socially. This means that by cooking and eating the individual is showing others facts about oneself. ${ }^{71}$ One fact communicated through this activity is the individual's personal food definitions. The importance of the social aspect of food consumption is also communicated as there is a vast difference between consuming food alone in the car and engaging socially over food. A good example of the power of cooking and food sharing is evident by the group Food Not Bombs, who collect, cook, and serve surplus food in cities all across North America. ${ }^{72}$ This group and collective kitchens more generally, are creating connections with and over food by circumventing the structural system that would oppose them. Collective kitchens can increase individual functioning by avoiding the structural system that promotes food related capability deprivation. Collective kitchens can be interpreted as one way to reduce food related capability deprivation.

\footnotetext{
${ }^{v}$ Extreme focus on food may be pathological in nature. (See end of Section)
} 
The Japanese philosopher Dogen articulates the manner in which we can begin to create our own food definitions. Individuals should

"slow the mind to the point that we experience what literally becomes us through a temporal process of eating. By slowing the mind we can be instructed by food about the inherent temporality and relationally of life..."73

The process of paying attention to the material consumed in this way allows the individual to make decisions regarding what types of materials they choose to consume and therefore make a part of themselves. This allows the individual to question the colloquial use of the term food and to personally redefine the term thereby potentially resolving food related capability deprivation. This mindful way of consuming food has emerged in several diet books in recent years. ${ }^{\text {vi }}$ Mindful eating has the potential to increase individual functioning with regard to food as the process of creating our own food definitions can accurately represent the individual's personal conception of the good.

Food related capability deprivation is fundamentally created as a result of the structural problems of the food supply system. It is because of this aspect of food related capability deprivation that the solutions will also be structural in nature. The individual can attempt to affect structural changes by increasing their functionings. An increase in individual functioning, or the individual's ability to realize their capabilities, has the potential to decrease food related capability deprivation.

Food movements may result in changes in food consumption habits which may have an effect on the larger food supply system. There is currently only one venue in

\footnotetext{
vi For example "Savor Mindful Eating Mindful Life" by Thich Nhat Hanh or "Eating Mindfully: How to End Mindless Eating \& Enjoy a Balanced Relationship to Food" by Susan Albers
} 
which to produce and procure food, but if alternative food movements grow there may be real choice in the food marketplace. New food marketplaces will most likely structure the production and distribution of food in vastly different ways which may result in a dramatic change in diet for some individuals. For example, the current year-round availability of fruits and vegetables is only possible within the current food supply system and is most likely impossible within a supply system with dramatically shortened supply lines. Additionally, some every-day products may become viewed (and priced) as luxury items.

Currently, Americans spend less than ten percent of their income on food. They also spend less than half an hour a day preparing meals and a little more than an hour enjoying them. ${ }^{74}$ If individuals begin in increase their capabilities with regard to food, their conception of the good with regard to food may include factors that necessitate a personal increase in time spent concerning food. For example, a shift away from the conventional grocery store may require consumers to change their shopping behavior. Individuals may shift towards buying in bulk and/or directly from the supplier. The planning and execution of this type of shopping behavior will require foresight, planning and effort. This will have the consequence of affecting other industries. Changes in shopping behavior toward less processed foods may require an increase in food preparation time. If more time and money are spent on food and food preparation, other industries will likely be affected.

Resolving food related capability deprivation does not necessarily lead to harmony with nature. For instance, environmental issues are not inherently resolved within any system that claims to resolve food related capability deprivation. One may 
assume that producer/consumer relationships would ensure that environment concerns are considered but this is not inherently true. Producers in an effort to increase production, especially in cases of high consumer demand, may not take into consideration the environmental consequences of certain behaviors. ${ }^{\text {vii }}$ Additionally, food related health concerns are unlikely to be universally resolved. With the resolution of food related capability deprivation individuals will have more freedom to create their own definitions regarding food. This may or may not result in healthy food definitions. However, a general increase in health will likely occur as individuals are unlikely to reach for ethoyglated diglycerides or high fructose corn syrup given the choice. ${ }^{75}$

Under a structural system that allows and encourages individuals to develop their own conception of the good with regard to food, individuals may be more personally responsible for their health than can be claimed within the current food supply system. This has worrying consequences as proposing a system in which individuals are entirely blamed for their food related health concerns is difficult to support. However, due to the unique, simultaneously internal and external qualities of food, food related capability deprivation is unlikely to be completely eradicated. It is also because of these properties of food that individuals cannot be completely responsible for food related health problems. As Fischler concludes there may be

"a fundamental anxiety in man's relationship to his food resulting not only from the need to distrust new or unknown foods, but also and more importantly from the tension between the two contradictory and equally constraining imperatives of the omnivore's double bind." 76

\footnotetext{
vii The raising popularity of fiddleheads are threatening the long term sustainability of fiddleheads and their environments. "Lovavores, beware" Globe and Mail, Sarah Elton, 20 May 2009
} 
The unique characteristics of food may cause concern that the personal resolution of food related capability deprivation necessitates an extreme and possibly neurotic focus on food. The rise in the 'foodie' culture rampant in Western countries can be explained as a personal attempt to resolve food related capability deprivation that remains structural in origin. 'Foodies' are attempting to resolve food related capability deprivation while remaining loyal to the dominate conception of the good with regard to food. This is what makes the 'foodie' culture pathological in nature as it prevents the individual from resolving food related capability deprivation. ${ }^{\text {viii }}$ However, within a structural system that reduces food related capability deprivation there would still be problems with regard to food related capabilities due to the nature of food and our relationship to it.

\section{Conclusion}

What would happen if structural changes as well as an increase in participation in food movements occurred? What would the food supply system look like if individuals experienced an increase in capabilities and functionings with regard to food? Some may propose that the traditional, family farm is the solution to food related capability deprivation and many writers illustrate the environmental stewardship, ecological balance and social harmony that traditional family farms offer. However, James E. McWilliams argues that this picture has been created by popular misunderstandings regarding agriculture. He believes that

"this misunderstanding ultimately boils down to the misleading allure of a lost golden age of food production - a golden age of ecological purity, in which the

\footnotetext{
vill There is an interesting classification of types of eaters in Elizabeth Telfer, Food for Thought: Philosophy and Food (London: Routledge, 1996)
} 
earth was in balance, humans collectively respected the environment, biodiversity flourished, family farms nurtured morality, and ecological harmony prevailed."

McWilliams maintains that no such golden age exists but rather that the very act of agriculture goes against the principles of ecological balance.

Even if such a golden age of agriculture exists modern society would be hard pressed to return to it because farming has been too thoroughly industrialized. Wendell Berry maintains that family farms are failing as a direct result of the universal adoption of industrial values. Industrial values maintain that the value of something equates to its price on the marketplace. Maintaining that there is no fundamental difference between a factory and a farm because all relations can be understood in mechanical terms is a byproduct of industrial values. Industrial beliefs also maintain that the primary human motivation is competition. In general, Berry believes that the "...family farm is failing because it belongs to an order of values and a kind of life that are failing." were prevalent in a society in which the dominate metaphors were organic. ${ }^{79}$ It seems unlikely that we can simply return to family farm, even if they could feed the current population, because the industrial values that promote a system of food related capability deprivation are so thoroughly engrained in modern society.

In conclusion, the modern world experiences capability deprivation as a result of the food supply system as this system fundamentally interferes with the ability of individuals to live according to their own conception of the good with regard to food. The food supply system creates problems relating to ignorance, instability, and source which highlights the ways in which the state is non-neutral with regard to food. This interferes with the individual's ability to form and live out their own conception of the good with 
regard to food. Nussbuam's capability of health and safety and of free association, as well as the development of the individual's conception of the good articulates the ways in which the modern food supply system creates food related capability deprivation. Structural and personal solutions were then presented which coincide with existing structural changes and food movements to highlight potential ways in which the individual can increase their capabilities and functionings with regard to food. Solutions to food related capability deprivation will likely not have us living in exactly the same manner as we currently do, but increasing food related capabilities does not require a return to some idyllic version of the past either. It is implausible to propose a solution to food related capability deprivation that aims to replace the dominate food supply system entirely rather individuals should be encouraged to use creativity and ingenuity to resolve the food related capability deprivation caused by industrial agriculture while maintaining a semblance of our current lifestyle. 


\section{End Notes}

1. Martha C. Nussbaum, Creating Capabilities (London, The Belknap Press of Harvard University Press, 2011) $x$

2. Martha C. Nussbaum, Frontiers of Justice (London, The Belknap Press of Harvard University Press, 2006) 77

3. Martha C. Nussbaum, Frontiers of Justice 70

4. Martha C. Nussbaum, Frontiers of Justice 70

5. Martha C. Nussbaum, Creating Capabilities 18

6. Martha C. Nussbaum, Creating Capabilities 18

7. Martha C. Nussbaum, Creating Capabilities 25

8. Martha C. Nussbaum, Creating Capabilities 25

9. Martha C. Nussbaum, Creating Capabilities 26

10. Martha C. Nussbaum, Frontiers of Justice 71

11. Martha C. Nussbaum, Creating Capabilities 57

12. Martha C. Nussbaum, Frontiers of Justice 164

13. Martha C. Nussbaum, Frontiers of Justice 75

14. Martha C. Nussbaum, Creating Capabilities 16

15. Martha C. Nussbaum, Frontiers of Justice 71

16. "Introduction," Perfectionism and Neutrality, ed Steven Wall and George Klosko (New York, Rowman \& Littlefield Publishers, Inc, 2003) 1

17. Ronald Dworkin, "Liberalism, in Public and Private Morality" Perfectionism and Neutrality, ed Steven Wall and George Klosko (New York, Rowman \&

Littlefield Publishers, Inc, 2003) 32

18. "Introduction," Perfectionism and Neutrality 2

19. Martha C. Nussbaum, Frontiers of Justice 70

20. "Introduction", Perfectionism and Neutrality 19

21. "Introduction", Perfectionism and Neutrality 13-15

22. Martha C. Nussbaum, "Human Capabilities, Female Human Beings", Women, Culture and Development, ed Martha Nussbaum and Jonathan Glover (Oxford, Clarendon Press, 1995) 21

23. Martha C. Nussbaum, Creating Capabilities 19

24. Peter Singer, Animal Liberation (New York, Harper Collins Publishers, 2002) 97

25. Michael Pollan, The Omnivore's Dilemma (New York, Penguin Books, 2006, 56

26. Michael Pollan, The Omnivore's Dilemma 62

27. Peter Singer and Jim Mason, The Ethics of What we Eat Why our Food Choices Matter (United States, Rodale, 2006) 15

28. Michael Pollan, The Omnivore's Dilemma 60

29. Wendell Berry, Bringing it to the Table On Farming and Food (United States, Counterpoint, 2009) 24

30. Martha C. Nussbaum, Frontiers of Justice 76

31. Thomas Pawlick, The End of Food (Toronto, Greystone Books, 2006) 118

32. Pawlick, 118-120

33. Berry, 24 
34. Great Lakes Echo, Poisoning Michigan: Author revisits PBB crisis 30 years later, http://greatlakesecho.org/2010/06/04/poisoning-michigan-an-author-revisits-themost-widespread-contamination-30-years-later/ (4 June 2010)

35. Michael Pollan, In Defense of Food an Eaters Manifesto (New York, Penguin Press, 2008) 160

36. Sandor Ellix Katz, The Revolution will not be Microwaved Inside America's Underground Food Movements (Vermont, Chelsea Green Publishing, 2006) 14

37. Martha C. Nussbaum, Frontiers of Justice 77

38. Sandor Ellix Katz, xiv

39. David C. Korten, "The Failures of Bretton Woods", The Case Against the Global Economy eds Jerry Mander and Edward Goldsmith (San Francisco, Sierra Club Books, 1996) 26-27

40. Karen Lehman and Al Krebs, "Control of the World's Food Supply", The Case Against the Global Economy eds Jerry Mander and Edward Goldsmith (San Francisco, Sierra Club Books, 1996) 123-125

41. Pollan, The Omnivore's Dilemma 94

42. Jonathan Wolff, Why Read Marx Today? (Oxford: Oxford University Press, 2002) 31

43. Sally Miller, Edible Action Food Activism and Alternative Economics

(Winnipeg, Fernwood Publishing, 2008) 23

44. Sally Miller, 23

45. Sally Miller, 23

46. Sally Miller, 23

47. Pollan, The Omnivore's Dilemma $94-95$

48. Pollan, The Omnivore's Dilemma 20

49. Martha C. Nussbaum, Creating Capabilities 31

50. Martha C. Nussbaum, Frontiers of Justice 155

51. Martha C. Nussbaum, Creating Capabilities 14

52. Martha C. Nussbaum, Creating Capabilities 32

53. Martha C. Nussbaum, Creating Capabilities 34

54. Martha C. Nussbaum, Frontiers of Justice 77

55. Martha C. Nussbaum, Frontiers of Justice 77

56. Sharon Astyk and Aaron Newton, A Nation of Farmers (Canada: New Society Publishers, 2009) 265

57. Sally Miller, 131

58. E.N. Anderson, Everyone Eats Understanding Food and Culture (New York: New York University, 2005) 124

59. Leon Rappoport, How we Eat Appetite, Culture, and the Psychology of Food (Toronto, ECW Press, 2003) 104-105

60. Amartya Sen, Development as Freedom (New York: Anchor Books, 2000) 160

61. Thomas A. Lyson, "Civic Agriculture and the North American Food System", Remaking the American Food System eds. C. Clare Hinrichs and Thomas A. Lyson (Lincoln, University of Nebraska Press, 2007) 19-27

62. Thomas A. Lyson, 28-29

63. Sally Miller, 15 
64. Sally Miller, 92

65. Sally Miller, 152

66. Julie E. Labelle, 2002. Beyond Food as Fuel: A socio-cultural analysis of the Slow Food Movement. Masters Thesis, University of Victoria, British Columbia, 2-3

67. Sandor Ellix Katz, 298

68. Sandor Ellix Katz, 300

69. Dogen, "Tenzo Kyokun", Cooking, Eating, Thinking Transformative Philosophies of Food, ed Deane W. Curtin and Lisa m Heldke (Indiana, Indiana University Press, 1992) 281

70. Dogen, 284

71. E.N. Anderson, 124

72. Sandor Ellix Katz, 290

73. Deane W. Curtin, "Food/Body/Person," Cooking, Eating, Thinking Transformative Philosophies of Food, ed Deane W. Curtin and Lisa $m$ Heldke (Indiana, Indiana University Press, 1992) 127

74. Pollan, In Defense of Food 145

75. Pollan, In Defense of Food 159

76. Claude Fischler. "Food, Self and Identity" Social Science Information, Vol 27, No 2, 1988278

77. James E. McWilliams, Just Food (New York, Back Bay Books, 2009) 6

78. Berry, 36-37

79. Berry, 19 


\section{Literature Review}

Food as a source of philosophical inquiry:

1. Pollan, Michael. The Omnivore's Dilemma A Natural History of Four Meals. United States: Penguin Books, 2006

2. Heldke, Lisa. "The Unexamined Meal is not Worth Eating: Or, Why and How Philosphers (Might/Could/Do) Study Food." Food, Culture, And Society. Vol 9, No 2, Summer 06: 201-219

3. Brillat-Savarin, Jean Anthelme. The Physiology of Taste. USA: Everyman's Library, 2009

4. Curtin, Dean W. and Lisa M. Heldke, eds. Cooking, Eating, Thinking Transformative Philosophies of Food. Indiana: Indiana University Press, 1992

5. Singer, Peter. Animal Liberation. New York: Harper Collins Publishers, 2002

6. Foer, Jonathan Safran. Eating Animals. New York: Little, Brown and Company, 2009

Agricultural Overview:

1. Lehman, Karen and Al Krebs "Control of the World's Food Supply" in The Case Against the Global Economy ed by Jerry Mander and Edward Goldsmith. Sierra Club Books: San Francisco, 1996. (122 - 130)

2. Berry, Wendell. Bringing it to the Table. Berkeley:Counterpoint, 2009

3. Standage, Tom. An Edible History of Humanity. New York:Walker and Company, 2009

4. Fairlie, Simon. Meat a Benign Extravagance. Vermont:Chealsea Green Publishing, 2010

Capabilities:

1. Nussbaum, Martha C. Frontiers of Justice Disability, Nationality, Species Membership. London: The Belknap Press of Harvard University Press, 2006

2. Nussbaum, Martha. C. Creating Capabilities The Human Development Approach. London:The Belknap Press of Harvard University Press, 2011

3. Nussbaum, Martha. C. "Human Capabilities, Female Human Beings" in Women, Culture, and Development A study of Human Capabilites ed Martha Nussbaum and Jonathan Glover. Clarendon Press: Oxford, 1995 (61-104)

4. Sen, Amartya. "Capability and Well-Being" in The Quality of Life. Clarendon Press: Oxford, 1993. Eds. Martha Nussbaum and Amartya Sen. 30-53

5. Sen, Amartya. Commodities and Capabilities. New York: Oxford University, 1985

6. Robeyns, Ingrid. "The Capability Approach in Practice" The Journal of Political Philosophy. Vol 14. No 3, November 2006: 351-376

7. Kuklys, Wiebke. Amartya Sen's Capability Approach: theoretical insights and empirical applications. New York: Springer, 2005 
Food related Capability Deprivation:

1. Pawlick, Thomas. The End of Food. Toronto: Greystone Books, 2006

2. Wittman, Hannah and Annette Aurelie Desmarais and Nettie Weibe, eds. Food Sovereignty Reconnecting Food, Nature and Community. Winnipeg: Fernwood Publishing, 2010

3. Fischler, Claude. "Food, Self and Identity" Social Science Information, Vol 27. No 2, 1988, 275-292

Alternatives:

1. Miller, Sally. Edible Action Food Activism and Alternative Economics. Winnipeg: Fernwood Publishing, 2008

2. Astyk, Sharon and Aaron Newton. A Nation of Farmers. British Colombia:New Society Publishers, 2009

3. Katz, Sandor Ellix. The Revolution will not be Microwaved Inside America's Underground Food Movements. Vermont: Chelsea Green Publishing, 2006

4. McWilliams, James E. Just Food. New York: Little, Brown and Company, 2009

Relevant Theoretical Works:

1. Wolff, Jonathan. Why Read Marx Today? Oxford: Oxford University Press, 2002

2. Dworkin, Ronald. "Liberalism" in Perfectionism and Neutrality Essays in Liberal Theory ed. Steven Wall and George Klosko. Rowman \& Littlefield Publishers, Inc.:New York, 2003 (31-40)

Wall, Steven and George Klosko, eds Perfectionism and Neutrality Essasy in Liberal Theory. Rowman \& Littlefield Publishers, Inc. : New York, 2003 


\section{A. Food as a source of philosophical inquiry}

Traditional Western philosophy has not taken food seriously as a means, mode, or starting point of philosophical inquiry. However, the very nature of food (simultaneously self and other) combined with the inherent tension between that which we can eat and that which we should eat (articulated by Pollan as the omnivore's dilemma) creates a unique, interesting, and complicated field of inquiry. This field of inquiry has been almost completely ignored by modern philosophy. However, Heldke believes that an important precedent exists in Platonic theory for taking food seriously as a source of philosophical inquiry. Heldke believes that food ought to be a source of philosophical inquiry because food is a primary source of meaning and value in human life. The work of Brillat-Savarin serves as a historical example of one way in which food can serve as the source of philosophical inquiry.

The anthology compiled by Curtin and Heldke illustrates the difference between Western philosophical inquiry and Eastern religious philosophies. While food has been largely ignored within Western philosophy, Eastern religions articulate the philosophical importance of a personal connection to food. This can be seen through the religious observation of meals in monasteries. This anthology is an exploratory study of the ways in which Western philosophical inquiry can begin to articulate, frame, and resolve problems surrounding food.

Peter Singer's book, Animal Liberation, is the ideal example of the way in which Western philosophy frames questions surrounding food. Western philosophy only understands food as a means of philosophical inquiry when it is framed in either animal rights concerns or environmental concerns. This framework, while beneficial, cannot 
offer insights into many aspects food. For example, animal rights and environmental concerns cannot address issues relating to the internal relationship created over food, the social implications of food, the aesthetic nature of food, or many other potential forms of inquiry. Therefore, while animal and environmental concerns are important food as a source of philosophical inquiry can, and should entail much more than animal rights and environmental concerns.

Pollan, Michael. The Omnivore's Dilemma A Natural History of Four Meals. United States: Penguin Books, 2006

Pollan begins by presenting the facts and history of industrial farming. Industrial farming emerged as a consequence of a dramatic change, the invention of man-made fertilizer, which allowed (and encouraged) a shift from total reliance on the sun, to a system based on fossil fuels. It was this reliance on fossil fuels which encouraged industrial agriculture to be managed solely on economic terms. This history is important as it begins to establish a framework in which we, as consumers and academics, can begin to understand the importance of food. Industrial eating has eroded, obscured, and eradicated the relationships between food, producer, and consumer. Pollan presents alternatives to industrial agriculture carefully, recognizing that food production is a complex system that requires careful thought and consideration. Pollan's journalist background makes him prone to explaining concepts with anecdotal evidence which, on occasion, leave his conclusions lacking. For example, he claims that the free market does not work in agriculture but simply uses a lengthy quote as proof. (54) However, regardless of the organization of food production and distribution, food will always 
remain a source of philosophical inquiry because of the very nature of food, or because of the omnivore's dilemma.

Heldke, Lisa. "The Unexamined Meal is not Worth Eating: Or, Why and How Philosphers (Might/Could/Do) Study Food." Food, Culture, And Society. Vol 9, No 2, Summer 06: 201-219

Heldke believes that an important precedent exists for seeing food as a philosophically relevant source of inquiry due to her careful re-understanding of Platonic works. Furthermore, Heldke believes that food ought to be a source of philosophical inquiry because food is a primary source of meaning and value in human life. Food can be used as source of philosophical inquiry in a variety of philosophical fields. Heldke proposes a series of ways in which philosophy as a discipline can begin to approach food philosophically. Philosophers can apply established philosophical categories to new foodrelated topics. Philosophers can continue an existing philosophical discussion but situate that discussion within philosophy of food. For example, vegetarianism which is currently discussed with regard to animal rights can be rearticulated through a discussion regarding personal and social motivations regarding food definitions. Philosophers can reclaim and rediscover previous philosophical work as relevant to philosophy of food. Additionally, philosophers can rephrase and recast familiar philosophy questions as questions regarding philosophy of food. Heldke then articulates specific existing philosophical frameworks in which philosophy of food can be explored. For example, aesthetics, ethics, social and political philosophy, ontology and epistemology can all be used to be articulate and answer philosophical questions that are food related. This exploratory article begins to 
show the ways in which philosophy, as a discipline, can begin to take food seriously as a source of philosophical inquiry. Due to the exploratory nature of this article, Heldke is unable to make specific claims about the nature or conclusion of these philosophical inquiries.

Brillat-Savarin, Jean Anthelme. The Physiology of Taste. USA: Everyman's Library, 2009

Brillat-Savarin's work is historically important as it offers a precedent from which to consider food as a source of philosophical inquiry. Brillat-Savarin explores concepts that are important to anyone considering food academically such as the definition of food, the difference between pleasures of the table and the pleasures of eating, and the widespread effects of gourmadism. However, he also includes outdated chemistry, scientific postulating, and anecdotes that are irrelevant. Generally, this work helps the modern academic to view food as a source of philosophical inquiry although BrillatSavarin himself worried about the academic and social consequences of doing so. (18)

Curtin, Dean W. and Lisa M. Heldke, eds. Cooking, Eating, Thinking Transformative Philosophies of Food. Indiana: Indiana University Press, 1992

This anthology offers ways to understand food philosophically that both legitimates new categories of inquiry (for example, the epistemology of food and the ontology of food), and offers ways to provide further illumination to traditional philosophical problems. Food can be understood philosophically by exploring the ways in which food helps to structure and define personhood. Understanding food philosophically 
can exposit moral arguments, as what the individual chooses to regard as food reflects who they are morally and has implications for the value placed on other human beings, the environment, and animals in general. Inquiring philosophically into food production and cooking may present an understanding of work in which there is no distinct dividing line between theory and practice. Food is a somewhat more accepted source of inquiry in political and social philosophy as the connections and complications between the individual and the corporation are frequently exposited within these disciplines. Western philosophers have persistently ignored, or marginalized food, one of the most common and pervasive sources of value in human experience. This anthology intends to show the value of using food as source of philosophical inquiry. Specifically, it articulates the philosophical importance of a personal connection to food. The Japanese philosopher, Dogen articulates this connection through his discussion of an authentic presence to food. (127) This anthology frequently includes memoirs, conversations, essays, and literary excerpts that are not specifically philosophical in nature. These inclusions are meant to articulate and clarify specific philosophical ideas.

\section{Singer, Peter. Animal Liberation. New York: Harper Collins Publishers, 2002}

This book, and Singer's work more generally, is an example of the current state of food as a source of philosophical inquiry in which animal rights are viewed as a legitimate source of inquiry while food, more generally, remains outside the realm of the philosophical. Singer articulates the ethical and moral issues resulting from the consumption of meat and exposits the horrors of industrial agriculture for the purpose of articulating the case against speciesism. Singer believes that while factory farming is 
especially violent to animals, so too are family farms with their practices of castration, dehorning, branding, and eventual death. Discussions regarding speciesism raise important philosophical questions however due to the nature of the philosophical inquiry the conclusions remain inapplicable to philosophical questions regarding food as a primary source of philosophical inquiry. The included data regarding the facts of industrial agriculture articulate and exposits a myriad of reasons why industrial agriculture is less than desirable.

Foer, Jonathan Safran. Eating Animals. New York: Little, Brown and Company, 2009

While this book is collection of thoughts, quandaries, and issues that one man delves through in order to personally determine what he should feed his newborn son it also places food in its proper philosophical place. Food matters to Foer (and to philosophers) because " his physical health matters, the pleasure of eating matters, and because the stories that are served with food matter. These stories bind our family together, and bind our family to others." (11)As Foer tells the stories of his grandmother's food, how she survived the war, and her current hoarding of food we can see that food is important for more than sustenance. This book illustrates how individuals are wrestling with the place of food in their lives and points to the ways in which philosophers can help them articulate, formulate and resolve food related quandaries. Foer comes to the conclusion that vegetarianism will resolve his concerns regarding food but acknowledges that "it is a commitment made within the context of my life, not anyone else's. And until sixty or so years ago, much of my reasoning wouldn't have even 
been intelligible, because the industrial animal agriculture to which I'm responding hadn't become dominant." (198) This personal memoir illustrates the timeliness and ultimate importance of food as a source of philosophical inquiry.

\section{B. Agriculture Overview}

The state of agriculture is dismal for which there are many reasons. Corporate control over the food supply system may be the direct cause but farmers are not without blame. As Standage shows the farm itself is fundamentally non-natural. This is because farms colonized, changed, and made dependent the wild grasses and grains of our forefathers. As members of modern, urban society we tend to idealize the small family farm which Wendell warns against. For just because a farm is small does not meant that the farm is sustainable, environmentally aware, or that animal rights are considered. Wendell warns against a view that articulates the notion that we, as a society, can simply return to small family farming. We cannot because the motivation behind farming has changed from social, environmental and/or personal to industrial. The farm has become a cog in the industrial wheel. To resolve the problems of corporate control over our food supply the small family farmer has to take responsibility for their part in the loss of agricultural knowledge and importance in our society. The farmer has to emerge as an expert in food production, land management, and animal husbandry. Farilie offers one way in which the farmer can spearhead changes in food production through his expose of default livestock. 
Lehman, Karen and Al Krebs "Control of the World's Food Supply" in The Case Against the Global Economy ed by Jerry Mander and Edward Goldsmith. Sierra Club Books: San Francisco, 1996. (122 - 130)

The problems of the food supply system can be linked to domestic and international government policies that have intentionally or inadvertently strengthened corporate power over the food supply system. The global economy threatens food security by separating consumers from producers and allowing corporations, with no allegiance to countries or their citizens, full reign of the food supply system. The current food supply system is a system in which a single company sells seed to the farmer, operates the local grain elevator, owns the railroad and the port facility, buys the grain from the farmer and sells the grain to itself to be processed into food. The farmer is completely at the mercy of the corporation. (123) Those who promote the global economy believe that the rules for trade should be based on comparative advantage. The logic of comparative advantage dictates that countries should buy low and sell high regardless of a product's importance for the local culture and economy. Theoretically, this would lead to cheaper food for all of the world's consumers but in actually it leads to dependence on foreign food suppliers and local government policies that are destructive in order to maintain their comparative advantage in a given market. While the world's governments could change global trade policy to favor domestic food security over comparative advantage this is unlikely as it would require controlling corporate behavior to a degree that most governments have been reluctant to express. (126) For the purposes expressed here, this article articulates the economic position that individual farmers are forced into as a result of corporate and governmental decisions. 


\section{Berry, Wendell. Bringing it to the Table. Berkeley:Counterpoint, 2009}

This series of essays and excerpts from previous written works by Berry when collected under one title gives the reader a (somewhat idyllic) impression of family farming in the past and one is meant to compare this impression to the horrors of the modern industrial farm. Berry's views on farming are most concisely articulated in one essay entitled "A defense of the Family Farm". Upon articulating a definition of the family farm, Berry articulates that the family's connection to the farm is easy to sentimentalize and while he believes that familiarity tends to mitigate abuse this mitigation is not a necessary condition on family farms. Berry believes that family farms offer solutions to political and cultural problems as well as to agricultural problems. Political and cultural problems arise because a worker's mind is degraded by loss of responsibility and loss of judgement which is caused by a shift from 'making' towards 'doing'. The family farm is failing because of the universal adoption of industrial values which are based on assumptions that do not apply to life on a family farm. Berry believes that farmers have to rediscover their responsibility for the adoption of industrial values. This statement aligns with the solutions proposed later in the anthology when Berry states that farmers have the potential, and responsibility, to "find their way out of the gyp known as the industrial economy." (45) 
Standage, Tom. An Edible History of Humanity. New York:Walker and Company, 2009

Standage adamantly supports the notion that farming, and all of the resulting products can, and should be, viewed as man-made. He believes that corn should be viewed as manmade because the current incarnation is a complex technology, which is the direct result of the human propagation of certain genetic mutations that have transformed a simple grass into a product that can no longer survive in the wild. While farming is more productive in the sense that it produces more food per unit of land, farming is less productive when measured by the amount of food produced per hour of labor. Additionally, there is evidence to suggest that farming results in a less varied and less balanced diet than hunting and gathering does. The simple truth, for Standage, is that farming is profoundly unnatural. Standage's view is important to consider, but does not mean that the complete eradication of farming is viable because farm based technologies have allowed and encouraged industrial specialization. Countries are able to produce industrial goods (which do not require a lot of land) and trade them for food (which does), allowing countries' populations to no longer be limited by the amount of land available for food production. Standage's view is important because even though farming may be unnatural because of the population growth that agricultural (and industrial) production initiated it would be difficult to return to a global hunter gatherer lifestyle and therefore we have to explore viable alternatives both within and extraneous to farming. Standage's view reminds us that assumptions regarding the natural/non-natural should be carefully examined. 
Fairlie, Simon. Meat a Benign Extravagance. Vermont:Chealsea Green Publishing, 2010

Fairlie offers a detailed explanation regarding the facts of meat production that present meat as an extravagance. Fairlie is not interesting in moral claims regarding animal rights but is instead concerned with the environmental ethics of eating meat. The central question then becomes whether or not farming animals for meat is sustainable. The inefficiency of meat production has always been the main environmental objective to its consumption. Farilie uses scientific data to articulate the ways in which meat production is inefficient. However, he ultimately views meat as a benign extravagance even in cases of proper production and distribution of meat. Default livestock are situations in which the primary reason for keeping animals is not to provide food as animals are integrated into a complex cropping and fertility cycle. The role of animals in a default economy is to consume waste, surplus, and marginal biomass and to provide services such as traction. Meat is a by-product or co-product of this system. Within a default economy, animals would only be raised as the primary product in systems, such as pastoral environments when there is no viable alternative. A fair amount of meat and meat products would be produced in this system. Additionally, animals can provide food security to the landless. The landless, almost by definition, cannot own vegetation however the mobility of animals allows the landless to sequester vegetation in either meat or milk form. This work is full of scientific information that has not been covered here, but from this resource we can conclude that there is a place for meat in the modern diet but it is not in the form of industrial farming. 


\section{Capabilities Approach}

The capabilities approach is a useful philosophical framework because the theory approaches humanity from a conception of human life that includes an innate understanding of human dignity. The state is supposed to provide its citizens the capabilities and functionings necessary to live according to their own conception of the good. Furthermore, a life lived without these capabilities and functionings is one without human dignity. This framework articulates life without human dignity as capability deprivation. The capabilities approach is one framework from within which the individual's relationship to food can be articulated, expressed, and questioned. The capabilities approach can illuminate the ways in which we, as individuals, experience capability deprivation in the area of food.

\section{Nussbaum, Martha C. Frontiers of Justice Disability, Nationality, Species} Membership. London: The Belknap Press, 2006

The capabilities approach is intended to provide the philosophical underpinning for an account of core human entitlements that should be respected and implemented by the governments of all nations, as a bare minimum of what respect for human dignity requires. The focus is on human capabilities, or what people are actually able to do and to be. Capabilities are informed by an intuitive idea of a life lived with dignity. The capabilities are specifically political goals as they can become the object of overlapping consensus among individuals or groups of people who otherwise have very different conceptions of the good. (70) Capabilities are opportunity for action, and not simply quantities of resources. The state should ensure that each individual has a threshold level 
of capability but the capabilities approach is not intended to provide a complete account of social justice as it does not claim to resolve issues of justice and distribution that would arise once all citizens are above the threshold level. (75)

The capabilities approach can be applied, and offer insight into the modern relationship with food because the list presented by Nussbaum is based on intuition and food is intuitively important. The same problems that arise for Nussbaum, will arise when the capabilities approach is applied to food. Nussbaum claims that adaptive preferences occur in which individual adjust their preferences to what they think they can achieve, and also to what society tells them is a suitable achievement is for someone like them. (73) Adaptive preferences are problematic for the application of the capabilities approach to food as adaptive preferences are frequently interpreted as the individual's actual preferences which can create the illusion that the current food supply system does not interfere with the individual's capabilities.

Nussbaum, Martha. C. Creating Capabilities The Human Development Approach. London:The Belknap Press of Harvard University Press, 2011

Here Nussbaum attempts to provide the general public and instructors of undergraduate courses a comprehensive text that outlines the basic aspects of the capabilities approach in a way that is accessible. It is for this reason that Nussbaum uses a particular example of an Indian woman in order to illustrate the consequences of capability deprivation and the effects in terms of quality of life of an improvement in capabilities. The central capabilities are then articulated and specific theoretical choices are explained. The capabilities approach is then explored in juxtaposition of various other 
development theories, like the GDP approach. This text articulates similar theoretical constructs as Nussbuam's other work but its goals of accessibility result in a more concise explanation of the capabilities approach.

Nussbaum, Martha. C. "Human Capabilities, Female Human Beings" in Women, Culture, and Development A study of Human Capabilites ed Martha Nussbaum and Jonathan Glover. Clarendon Press: Oxford, 1995 (61-104)

Nussbaum claims that the capability approach has as its central task to focus " on what is common to all, rather than on differences, and to see capabilities and functionings as more central, more at the core of human life". (63) Nussbaum describes two distinct thresholds, "a threshold of capability to function beneath which a life will be so impoverished that it will not be a human at all; and a somewhat higher threshold, beneath which those characteristic functions are available in such a reduced way that, though we may judge the form of life a human one, we will not think it a good human life." (81) The second threshold is the one that public policy should aim to provide for its citizens. In many cases the move between the first threshold and the second is supplied by the individual's own powers of choice and self-definition such that once society places them above the first threshold, moving above the second is more or less up to them. In other cases, such as bodily health and nutrition, there is a considerable difference between the two thresholds. (81)

Nussbaum claims that the determination of whether certain individuals or groups are across the threshold is only as precise as the threshold and she believes that further clarification should be done by the community of nations. (87) However, as Nussbaum 
has previously stated, individual preferences are adaptive to what the individual and/or their society thinks they can achieve. Consequently, thresholds determined by the community of nations would reflect the opinions of those in power. This can be seen through expositing the food supply system in which individuals are capability deprived in the areas of health and safety and of free association because those in power limit the real choices of those below the threshold. Governments are meant to ensure that all human beings have the necessary resources and conditions for action, leaving the choice up to them. (95) However, due to the nature and structure of the food supply system, governments are actively interfering with the ability of individuals to choose for themselves.

Sen, Amartya. "Capability and Well-Being" in The Quality of Life. Clarendon Press: Oxford, 1993. Eds. Martha Nussbaum and Amartya Sen. 30-53

When discussing wealth, income is not desired for its own sake therefore any incomebased notion of poverty must refer, directly or indirectly, to the functionings which are achieved as a result of having income. (41) As a result of this interplay between income and functioning, especially in circumstances below a minimum threshold, an increase in either will result in an increase in capabilities. Additionally, it becomes possible to identify the minimum income necessary for reaching the threshold of that capability. Once the correspondence between income and capability is established it would not matter whether poverty was defined in terms of a failure of basic capability or as a failure to have the corresponding minimally adequate income. The benefits of using the capability approach are that it offers insight into the interpersonal and intersocial 
variables that affect functioning. (42) Discussion of this nature alludes to the insights that the capability approach may provide when food is considered. Both income and access to food are used as primary indicators of well-being. However, food is not desired for its own sake as food refers, directly or indirectly, to the basic nutritional needs it would meet if consumed. Food has the added benefit of being able to meet identity, social and community needs.

\section{Sen, Amartya. Commodities and Capabilities. New York: Oxford University, 1985}

Formal economics has not been very interested in plurality of focus when judging a person's states and interests which gives the economic approach a disadvantage because in taking a very narrow view of human beings (and their feelings, ideas, and actions) the economic approach is impoverished in the scope and reach of its economic theory. (2-4) In judging the well-being of a person, it would be erroneous to limit the analysis to the characteristics of the goods possessed, as we should also consider the individual's functioning, or what the person succeeds in doing with the commodities and characteristics in their possession. For example, the possession of food gives the owner access to the properties of food, which can be used to satisfy hunger, to yield nutrition, to give eating pleasure and to provide for social meetings. (9) Sen's articulation echoes Nussbaum's later list of capabilities and Sen points to some of the problems with the capability approach in saying, "a poor, undernourished person, brought up in penury, may have learned to come to terms with a half-empty stomach, seizing joy in small comforts and desiring no more than what seems 'realistic'. But this mental attitude does not wipe 
out the fact of the person's deprivation. Nor does it imply that the persons would not value the removal of that deprivation if it were to occur." (29)

\section{Robeyns, Ingrid. "The Capability Approach in Practice" The Journal of Political} Philosophy. Vol 14. No 3, November 2006: 351-376

The popularity of the capability approach raises questions regarding the application of the theory. (352) The capability approach is not a theory that can explain poverty, inequality, or well-being; instead it aims to provide concepts and a framework that can help to conceptualize and evaluate these phenomena. (353) Robeyns sees three major problems with the theory. These problems are the interplay between functionings and capabilities, the selection of relevant capabilities, and the issue of weighting the different capabilities. (353) The issue of weighting or trade-offs is important as it is this issue that can help explain the capability deprivation with regard to food. How should different capabilities be traded-off against each other, or how should an index of functioning be constructed? Nussbaum regards each capability as an entitlement that should never be sacrificed for another. She believes that the state should provide each citizen with a minimum threshold of each capability. However, while viewing capabilities as a fundamental entitlements may be a useful philosophical exercise it is of limited help in many instances of empirical evaluation and policy making. (357) The capability approach can offer innovative insight into current problems by offering the underpinnings of a multidimensional empirical analysis, and stresses to a far greater extend the need to integrate theory and practice, and to pay due attention to the 
philosophical foundations. The capability approach is extremely interdisciplinary, and perhaps even post-disciplinary. (371)

Robyens points to several important problems with the application of the capability approach. While Nussbaum remains adamant that the core capability should be provided by the state, the food supply system consistently puts the economic and legal needs of the corporation before the capabilities of farmers, food producers, and eaters. The approach requires a system in which to balance the needs of opposing parties. This problem is further aggravated by the threshold problem discussed previously. Regardless of the problems of application, the capability approach remains insightful due to its interdisciplinary nature.

Kuklys, Wiebke. Amartya Sen's Capability Approach: theoretical insights and empirical applications. New York: Springer, 2005

The capabilities approach operates at two levels. Realised welfare is measured by functioning and is one level in which the capabilities approach operates. The potential or feasible welfare which is measured in capabilities is the second. (12) It is because of the multifaceted nature of the capabilities approach that it has the potential to offer more detailed insight into individual well-being then a strictly economic approach. The capabilities approach takes into account the presence of non-economic resources. (5) The capabilities approach is an evaluative framework for individual welfare because on one level it is not the actual achievement that matters, but the potential achievement. (6) Sen suggests that individuals derive welfare both from the range of options in the choice set and from the possibility to perform the act of choice themselves. (16) By distinguishing 
between funtionings and capabilities, the capabilities approach can account for welfare derived from the chosen outcome (functioning) and welfare derived from the opportunity to choose (capabilities). The capabilities approach is able to offer insight, in a more direct and complete sense, regarding the importance of freedom of choice then monetary measures of welfare. (18) This characteristic of the capabilities approach leads to the conclusion that not all who are income poor are functioning poor and vice versa. (29) The importance, consequences, and theoretical focus of choice is important as it choice that offers individual's the real opportunity to live according to their own conception of the good.

\section{Food Related Capability Deprivation}

The capabilities approach can illustrate the ways in which we, as individuals, experience reduced capabilities, or choice, with regard to food. Pawlick articulates the mired of ways in which industrial agriculture reduce choice in the marketplace. The nutritional value of food has been in decline since the almost universal adaptation of industrial agriculture. These facts, combined with the universal nature of industrial agriculture reduce choice in the marketplace. Reduced choice equates to capability deprivation. The concept of food sovereignty and food security speak to attempts to increase capabilities. However, the industrialization and capitalization of food production as well as the commodification of food have radically altered our relationship to food, land and place. All of which result in capability deprivation. As Fischler states, our personal and social relationship to food is one way in which the individual lives or acts 
out their conception of the good. Therefore, capability deprivation in the area of food should be taken seriously as it affects the individual's human dignity.

\section{Pawlick, Thomas. The End of Food. Toronto: Greystone Books, 2006}

Pawlick aims to exposit the state of the current food supply system. Pawlick claims (with the USDA's informational backing) that the nutritional value of foods has been declining over the past fifty years. The decline in nutrients has allowed for an increase in extraneous toxic (or potentially toxic) contaminants in the food we eat. Pawlick blames the industrialization of agriculture for the shift in nutritional value of food. Specifically, he points to research that shows that the rise in man-made fertilizers increased food production, but decreased the nutritional value of the food produced. (89) In conjunction with the declining nutritional value of food, Pawlick exposits problems relating to pollution, natural habitat destruction, soil degradation, water waste, and loss of biodiversity. The solution to the problems of industrial agriculture is to simple return to growing one's own food either through family farming, gardening, or the support of such enterprises. Pawlick believes that 'agribusiness cannot be 'reformed', or pressured into becoming a reliable, responsible source of healthy food and a protector of the environment, any more than foxes could be trained to become guardians for the world's chicken coops.' (203) Pawlick believes that returning to small scale food production is the answer but he neglects to articulate the ways in which small scale food production would address issues relating to knowledge and population that may make widespread small scale farming inapplicable in the current age. Overall Pawlick exposits the current 
food supply system and articulates the reasons that one may seek alternatives and briefly and idyllically offers alternatives.

Wittman, Hannah and Annette Aurelie Desmarais and Nettie Weibe, eds. Food Sovereignty Reconnecting Food, Nature and Community. Winnipeg: Fernwood Publishing, 2010

Food sovereignty can be interpreted as the right of nations and people to control their own food system, including their own markets, production modes, food cultures and environments. Food sovereignty has emerged in response to the global control of the food production system. Food sovereignty seeks to delegitimize the corporate food production by questioning the increasingly global control of the food system and demanding control over food at lower levels. Food sovereignty aims to decentralize and democratize power in the food system rather than concentrate it within a handful of corporate monopolies. For the purposes explicit here, food sovereignty can be interpreted as a grassroots movement that aims to increase the capability of free association as food sovereignty aims to change relationships with food, agriculture, the environment and with each other. The industrialization and capitalization of food production and the commodification of food have radically altered our relationship to food, land and place which the food sovereignty movement aims to reverse. 
Fischler, Claude. “Food, Self and Identity" Social Science Information, Vol 27. No 2, 1988, 275-292

Food is central to our sense of identity but in order to clarify how and why food is so closely linked to identity one first needs to recall certain basic characteristics of the human relationship to food. Namely that it is multidimensional. The human relationship to food involves an omnivore's paradox in which the omnivore has the invaluable ability to live on a multitude of different foods but this also implies a need for variety as the omnivore cannot obtain all the nutrients needed from one food. A paradox lies in the tension between neophobia (fear or the unknown) and neophilia (the tendency to explore). Fischler concludes that there may be "a fundamental anxiety in man's relationship to his food resulting not only from the need to distrust new or unknown foods, but also and more importantly from the tension between the two contradictory and equally constraining imperatives of the omnivore's double bind." (278) In addition to the omnivore's paradox there is the issue of incorporation. Incorporation is the action in which "we send food across the frontier between the world and the self." (279) Incorporation effects the individual's sense of self but is also the basis for collective identity and of otherness as "the eater incorporates the properties of food but it also incorporates the eater into a group." (281) The question that Fischler asks, in response to information about the modern food supply system is "if we do not know what we eat, how can we know what we are?" (282) From the fact that food helps to create identity, both personal and socially, it becomes clear that free association with regard to food is important as free association allows the individual to live out their conception of the good with regard to food. 


\section{E. Alternatives}

While not framed from within the capabilities approach, there are many possible solutions to food related capability deprivation. Miller believes that changes in the personal relationship to food can have political and social consequences. Astyk and Newton believe that the solution to the problems of industrial agriculture (of which food related capability deprivation is one) is a reimagining of the future in which we incorporate current trends and motivations. Simply returning to small family farms is unlikely to be successful. Katz believes that this change will emerge as individuals begin to take personal responsibility for their food and to begin to, through food activism, act to change the system in which they disagree. McWiliams questions the notion that local food is a viable solution to the problems of industrial agriculture. McWilliams is correct in stating that the solution to food related capability deprivation and the other consequences of industrial agriculture will be multi-faceted in nature. Therefore, adherence to a complete local food paradigm seems unlikely and irresponsible. However, his insistence that we should be able to maintain, unaltered, our current lifestyle seems just as unlikely and irresponsible. Industrial agriculture is a recent invention therefore the lifestyle that accompanies it is just as recent and man-made. Our current lifestyle results in food related capability deprivation so it seems likely that the resolution of that deprivation will result in fundamental changes to industrial agriculture. It is implausible to propose a solution to food related capability deprivation that aims to replace industrial agriculture entirely rather individuals should be encouraged to use creativity and 
ingenuity to resolve problems of food related capability deprivation that emerges from industrial agriculture while maintain a semblance of our current lifestyle.

Miller, Sally. Edible Action Food Activism and Alternative Economics. Winnipeg: Fernwood Publishing, 2008

The 1978-1980 People's Food Commission was a series of informal hearings on food that inspired new ways of thinking about social change in Canada. Miller believes that when individuals express their concern over and about food they are also fighting about social change as food choices have political and social consequences. Miller explores these consequences by expositing and articulating the political and social problems that arise from widespread acceptance of GMO's as well as the current economic landscape. Positive food choices also have political and social consequences which can be seen through an increase in cooperatives, farmer's markets, and community gardens as well as the increasing importance of organic food. Miller's articulation of the widespread consequences of food choices foreshadows the effects of food related capability deprivation, as well as its resolution.

Astyk, Sharon and Aaron Newton. A Nation of Farmers. British Colombia:New Society Publishers, 2009

The authors begin with the simple premise that it is both possible and necessary to cease industrial agriculture because of the resource depletion, global warming, global poverty, increased food insecurity and hunger, and unsafe, low-quality food that is the product of the current food supply system. The solution to the ills of industrial agriculture 
is to simply choose to change the nature of what we grow and what we eat. The solution begins with the recognition that, out of necessity, we have to end dependency on fossil fuels and to view food security as a central issue. The solutions proposed are not idyllic as the authors "are not fundamentally interested in idealistic solutions but ones that are achievable. We do not claim that any solution we propose will eliminate problems of access, make all poverty disappear, or make the world a nobler place. What we do claim is that we can feed the planet as well or better without fossil fuels, and in relocalized, sustainable agriculture." (218) Small farms and victory gardens are proposed as solutions as small-scale polyculture is higher yielding, protects soil and water better, is less dangerous to the climate, less toxic, and if done locally everywhere that people live and need to eat, results in more secure food systems than industrial agriculture. Food production should be a community endeavour in which neighbors work with neighbours to grown their own food. Farming and gardening would entail an increase in the skills of cooking, thrift, food storage, and partial return to the informal economy. This concept is more realistic than proposing a return to widespread small family farms as the solution becomes a reimagining of the future, incorporating current trends and motivations, and not simply a return to the past.

Katz, Sandor Ellix. The Revolution will not be Microwaved Inside America's Underground Food Movements. Vermont: Chelsea Green Publishing, 2006

Katz believes that the individual should take some personal responsibility for their food and begin to, through food activism, act to change the system in which they disagree with. Currently, laws dictating food production are motivated by the model of mass 
production, where sterility and uniformity are important. These laws render much of the trade in local food technically illegal. Katz believes that the individual should be more connected to their food and water and outlines ways in which food activism promotes such connection. Katz supports such technically illegal activity because the current food supply system will (and does) have negative consequences. In order to change the current system, individuals must connect with food in sustainable, local and healthy ways. 'Eating well has become an act of civil disobedience.' (xiv) Katz articulates ways in which the individual can initiate structural changes through which current food related capability deprivation can be negated.

\section{McWilliams, James E. Just Food. New York: Little, Brown and Company, 2009}

The widely acclaimed solution to industrial agriculture is to produce and consumer locally grown food. McWilliams does not believe that eating locally is, in and of itself, a viable way to produce a globally sustainable food production system. He believes that there are more productive, creative and global ways to sustainably feed the world. As McWilliams states, "to be a centrist when it comes to food is, unfortunately, to be a radical". (5) The local food movement has focused, almost exclusively on food miles, or the distance our food travels before we eat it. McWilliams offers evidence to suggest that transportation is the lowest of all the energy consumption factors in food production. (26) The local food movement offers local food as a way to counter the global and "offers environmentalists otherwise deeply involved in a commercialized life an easy way to register their discontentment with the excesses of modernity" (30) McWilliams believes that such rhetoric does not allow a viable solution to the problems 
of the current food supply system to emerge. Buying locally produced food is smart when natural conditions justify the production of such goods however chances are slim that one local environment can sustainably accommodate the diverse range of goods that make up a healthy modern diet. Therefore, the new locavore challenge should be incorporating models of environmentally sound trade into their broader efforts to improve our food supply. (47) We can and should keep things local but we must also stop insisting that our behavior is, if universalized, a viable answer to the world's present and future food problems. (48) While McWilliams is correct in stating that the solution to food production will be multi-faceted, his insistence that we should be able to maintain, unaltered, our current lifestyle is difficult to comprehend. The local food movement should be working toward global sustainability, but that sustainability can be the result of a primarily local food economy.

\section{F. Relevant Theoretical Works}

Wolff, Jonathan. Why Read Marx Today? Oxford: Oxford University Press, 2002

Marx's concept of alienation is useful in articulating and illustrating food related capability deprivation. A dominate theme in Marx's early work is that the "capitalist society of his day is not properly fit for human consumption. It crushes the human spirit, denying the vast majority of people any chance to develop their real potential. No existing theorist, Marx thinks, has diagnosed the human malaise correctly, and thus no one had been in any position to outline a genuine cure, although this had not stopped them trying. Marx is confident that he can do better." $(50,13)$ It is Marx's theory of alienation and alienated labor that offers a critic of capitalism. It is the alienation of 
labour that interferes with our ability to enjoy that which makes us most distinctively human. Alienated labour has several distinct aspects. The first of which is alienation from the product. Alienation from the product has a simple understanding, in that we are separated from the end product of our labour, but can also be understood as collective alienation from the products we create. The economic marketplace is illustrative of collective alienation as the economic marketplace renders some forms of behaviour rational and others irrational which results in individual domination by the marketplace. The second aspect is alienation of productive activity which results from an elaborate division of labour. This "leads to a de-skilling of the worker, where each individual is reduced to performing a highly repetitive, mindless task, with little understanding of their place in the total process. (13) The third aspect of alienation of labour is alienation from our species-being. The alienation of labour has an intrinsic effect on the individual as part of what it means to be human is our ability to labour in a productive, meaningful way. The final aspect of alienation of labour is alienation from other human beings. The alienation of labour is the plight of the worker under capitalism in which "a person's essence becomes detached from his or her existence; i.e. that workers live in a way that does not express their essence." (30) Marx's conception of alienation of labour can be applied to illustrate the consequences of capability deprivation as alienation leads to reduced quality of life in much the same way that capability deprivation does.

Dworkin, Ronald. "Liberalism" in Perfectionism and Neutrality Essays in Liberal Theory ed. Steven Wall and George Klosko. Rowman \& Littlefield Publishers, Inc.:New York, 2003 (31-40) 
Wall, Steven and George Klosko, eds Perfectionism and Neutrality Essasy in Liberal Theory. Rowman \& Littlefield Publishers, Inc. : New York, 2003

An important aspect of the capabilities approach is that the state remains neutral in order to allow its citizens to exercise their freedom. Neutrality is the view that the state should not reward or penalize particular notions of the good life, but rather should provide a neutral framework within which different and potentially conflicting conceptions of the good can be pursued. The concept of neutrality can be summarized by saying "that political decisions must be, so far as is possible, independent of any particular conception of the good life or of what gives value to life. Since the citizens of a society differ in their conceptions, the government does not treat them as equals if it prefers one conception to another, either because the officials believe that one is intrinsically superior, or because one is held by the more numerous or more powerful group." $(42,32)$ The emergence of pluralistic societies sees a rise in the importance of neutrality because individuals in pluralistic societies hold different moral and religious views. Neutrality becomes important in order to determine the place of the state in the moderation of these various, and conflicting views. This type of mediation is difficult as there is no single conception of neutrality that is universally accepted. Neutrality is contrasted with the notion of perfectionism. Perfectionism is the idea that the state should not strive to be neutral between conceptions of the good, but should promote valid or sound conceptions of the good and discourage worthless ones. Perfectionists hold that the state should promote excellence and/or assist its citizens in their efforts to lead worthwhile lives, even if doing so requires the state to undertake political action that is controversial or coercive. This view holds that the state should, assuming that it is 
competent to do so, assist its citizens in their efforts to lead valuable lives. If successful, perfectionism is not antithesis to individual freedom because if “... it can be carried through successfully, then perfectionism, properly understood, will turn out to be supportive of, rather than hostile to, individual freedom. With this in mind, we shall stipulate that liberal perfectionism is a version of perfectionism that identifies perfectionist reasons for favoring limited government." (17) This is due to the notion that "if there exists a plurality of fully good ways of life, then perfectionists need not hold that the state should promote a single conception of the good life. They can argue that the state best promotes the good by providing conditions under which its citizens can pursue and realize a wide range of valuable activities and goods." (18) The distinction between neutrality and perfectionism is important to the wider understanding of the capability approach. As the capability approach requires state neutrality it is important to understand the theoretical consequences of various understandings of neutrality. 